\title{
CHARACTERIZATION AND CRYSTAL STRUCTURES OF NEW SCHIFF BASE MACROCYCLIC COMPOUNDS
}

\author{
A.D. Khala ji ${ }^{1}, S$. Ha fez Ghoran ${ }^{1}, M$. Pojarová ${ }^{2}, M$. Duš e $k^{2}$ \\ ${ }^{1}$ Department of Chemistry, Faculty of Science, Golestan University, Gorgan, Iran \\ E-mail: alidkhalaji@yahoo.com \\ ${ }^{2}$ Institute of Physics, Czech Academy of Sciences, Praha, Czech Republic
}

Received February, 24, 2015

\begin{abstract}
We report the synthesis and characterization of two new macrocyclic Schiff base compounds: a 15-membered (1) and 16-membered (2) one. Their synthesis involves a Schiff base condensation of 2,2-dimethylpropanediamine and two dialdehydes: 5,5'-dimethoxy-2,2'-(ethane-1,2diyldioxy)dibenzaldehyde and 5,5'-dimethoxy-2,2'-(propane-1,3-diyldioxy)dibenzaldehyde. The compounds are characterized by elemental analysis (CHN), FT-IR, ${ }^{1} \mathrm{H} \&{ }^{13} \mathrm{C}-\mathrm{NMR}$ spectroscopy, and single crystal X-ray diffraction. Compound 1 crystallizes in the monoclinic space group $C c$ with $a=11.0668(5) \AA, \quad b=11.7962(5) \AA, \quad c=17.1980(9) \AA, \quad \beta=103.611(5)^{\circ}$, $V=2182.08(18) \AA^{3}, Z=4, R\left[F^{2}>3 \sigma\left(F^{2}\right)\right]=0.048$ and $w R\left(F^{2}\right)=0.150$, while compound 2 crystallizes in the monoclinic space group $C 2 / c$ with $a=38.4782(15) \AA, b=5.6309(2) \AA$, $c=20.4029(7) \AA, \quad \beta=102.524(4)^{\circ}, \quad V=4315.4(3) \AA^{3}, \quad Z=8, \quad R\left[F^{2}>3 \sigma\left(F^{2}\right)\right]=0.051 \quad$ and $w R\left(F^{2}\right)=0.130$.
\end{abstract}

DOI: $10.15372 / \mathrm{JSC} 20150724$

Keywords: synthesis, macrocyclic Schiff base, single crystal structure analysis, spectroscopy.

Schiff base compounds are widely used ligands due to the ease of preparation and remarkable versatility. The ability to form stable complexes designates Schiff bases to play an important role in the development of transition metal coordination chemistry [ $1-10$ ]. The research field on Schiff base complexes is very broad because of their structural diversity and many potential applications [ $1-10$ ]. Macrocyclic Schiff bases have attracted much attention since the early 1980's. They can be prepared by condensation of different dicarbonyl groups with a wide range of different diamines [ $11-21]$. The direct preparation of free macrocyclic Schiff bases is sometimes complicated, and in such cases they must be prepared by the template effect [1,3]. Nevertheless, in recent years, considerable effort has been made to avoid the template effect in the preparation of macrocyclic Schiff bases [11-16], because the template effect has two substantial disadvantages. First, it does not allow one to synthesize metal-free macrocyclic compounds and the second, the template method usually affords symmetric macrocyclic complexes [13]. We report herein the direct synthesis, characterization, and crystal structures of two new Schiff base macrocycles (Scheme 1).

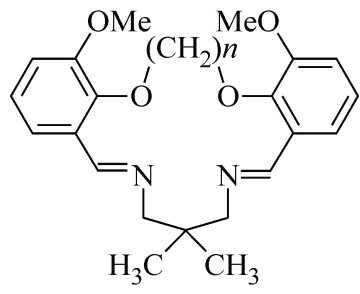

Scheme 1. Chemical structures of macrocylic Schiff bases $\mathbf{1}(n=2)$ and $\mathbf{2}(n=3)$

(C) Khalaji A.D., Hafez Ghoran S., Pojarová M., Dušek M., 2015 
Experimental. Materials and characterization. All reagents and solvents for synthesis and analysis were commercially available and used as received without further purifications. Infrared spectra were recorded using $\mathrm{KBr}$ disks on a FT-IR Perkin-Elmer spectrophotometer. Elemental analyses were carried out using a Heraeus CHN-O-Rapid analyzer. ${ }^{1} \mathrm{H}-\mathrm{NMR}$ spectra were measured on a BRUKER DRX-500 AVANCE spectrometer at $500 \mathrm{MHz}$. All chemical shifts are reported in $\delta$ units downfield from TMS. The dialdehydes 5,5'-dimethoxy-2,2'-(ethane-1,3-diyldioxy)dibenzaldehyde and 5,5'-dimethoxy-2,2'-(propane-1,3-diyldioxy)dibenzaldehyde were prepared according to the literature procedure $[22,23]$.

X-ray crystallography. Suitable single crystals of $\mathbf{1}$ and $\mathbf{2}$ were chosen for the X-ray diffraction study. Crystallographic measurements were performed at $120 \mathrm{~K}$ with a four circle Oxford Diffraction Gemini CCD diffractometer with mirrors-collimated $\mathrm{Cu} K_{\alpha}$ radiation $(\lambda=1.54184 \AA)$. The crystal structures were solved by direct methods using the SHELXS-97 program [24] and refined using the SHELX-97 program package [24] by the full-matrix least-squares technique on $F^{2}$. For the final refinement of 1 we used the Jana2006 program package [25 ]. The molecular structure plots were prepared using ORTEP III [26]. All hydrogen atoms were discernible in difference Fourier maps and could be refined to reasonable geometry. According to common practice $\mathrm{H}$ atoms bonded to $\mathrm{C}$ atoms were kept in ideal positions with $\mathrm{C}-\mathrm{H}=0.96 \AA$ while positions of $\mathrm{H}$ atom bonded to $\mathrm{O}$ atoms were refined freely. In both cases, $U_{\text {iso }}(\mathrm{H})$ was set to $1.2 U_{\text {eq }}(\mathrm{C})$ and $1.5 U_{\text {eq }}(\mathrm{O})$. Crystallographic data and details of the data collection and structure solution and refinements 1: $\mathrm{C}_{23} \mathrm{H}_{28} \mathrm{~N}_{2} \mathrm{O}_{4}, M=396.5$, monoclinic, space group $C c, a=11.0668(5), b=11.7962(5), c=17.1980(9) \AA, \quad \beta=103.611(5)^{\circ}, \quad V=$ $=2182.08(18) \AA^{3}, Z=4, \mu=0.67 \mathrm{~mm}^{-1}, 8562$ measured reflections, 2957 independent, 2819 observed $(I>3 \sigma(I)), R_{\text {int }}=0.041, S=3.19, R\left(F^{2}>3 \sigma\left(F^{2}\right)\right)=0.048, w R\left(F^{2}\right)=0.150,262$ parameters. (Final refinement of 1 was made by Jana2006. This package calculates the true goodness of fit $(S)$ based on the experimental weighting scheme while SHELX used for the refinement of $\mathbf{2}$ refines the weighting scheme and forces $S$ to be one. Large exposition times and strong bonding effects caused high $S$ for $\mathbf{1}$ ). 2: $\mathrm{C}_{24} \mathrm{H}_{30} \mathrm{~N}_{2} \mathrm{O}_{4}, M=410.50$, monoclinic, space group $C 2 / c, a=38.4782(15), b=5.6309(2), c=$ $=20.4029(7) \AA, \beta=102.524(4)^{\circ}, V=4315.4(3) \AA^{3}, Z=8, \mu=0.69 \mathrm{~mm}^{-1}, 28989$ measured reflections, 3862 independent, 2655 observed $(I>3 \sigma(I)), \quad R_{\text {int }}=0.103, \quad S=1.07, \quad R\left(F^{2}>3 \sigma\left(F^{2}\right)\right)=0.051$, $w R\left(F^{2}\right)=0.130,275$ parameters. (High $R_{\text {int }}$ was caused by low quality data with diffuse scattering and smeared and split diffraction spots.)

Synthesis of 1. 5,5'-Dimethoxy-2,2'-(ethane-1,3-diyldioxy)dibenzaldehyde $(0.2 \mathrm{mmol})$ and 2,2dimethylpropane-1,2-diamine $(0.2 \mathrm{mmol})$ were dissolved in methanol at room temperature. The mixture was stirred and heated for $60 \mathrm{~min}$ to give a clear solution. The mixture was then cooled and allowed to crystallize at room temperature. After keeping the solution in air for several days, by slow evaporation of the solvent colorless crystals were formed at the bottom of the vessel. The resulting crystals were collected by filtration and dried at room temperature. Yield: $73 \%$. Anal. Calc. for $\mathrm{C}_{23} \mathrm{H}_{28} \mathrm{~N}_{2} \mathrm{O}_{4}$ : C, 69.67; H, 7.12; N, 7.06 \%. Found: C 69.55, H 7.19, N 7.011\%. FT-IR (KBr, cm $\left.{ }^{-1}\right)$ : $1632(\mathrm{C}=\mathrm{N}) .{ }^{1} \mathrm{H}-\mathrm{NMR}\left(\mathrm{DMSO}-d^{6}, \delta(\mathrm{ppm})\right): 1.26(\mathrm{~s}, 3 \mathrm{H}), 3.35(\mathrm{~s}, 2 \mathrm{H}), 3.88(\mathrm{~s}, 3 \mathrm{H}), 4.47(\mathrm{~s}, 2 \mathrm{H}), 6.98$ $(\mathrm{dd}, 1 \mathrm{H}), 7.08(\mathrm{t}, 1 \mathrm{H}), 7.52(\mathrm{dd}, 1 \mathrm{H}), 8.75(\mathrm{~s}, 1 \mathrm{H}) .{ }^{13} \mathrm{C}-\mathrm{NMR}\left(\mathrm{DMSO}-d^{6}, \delta(\mathrm{ppm})\right): 25.85,37.05$, $55.89,67.89,72.49,76.81,77.07,77.33,114.18,119.25,123.83,130.42,147.59,152.44,159.36$.

Synthesis of 2. Compound 2 was synthesized using the same procedure as that for $\mathbf{1}$, except that 5,5'-dimethoxy-2,2'-(propane-1,3-diyldioxy)dibenzaldehyde was used instead of 5,5'-dimethoxy-2,2'(ethane-1,3-diyldioxy)dibenzaldehyde. Yield: $73 \%$. Anal. Calc. for $\mathrm{C}_{24} \mathrm{H}_{30} \mathrm{~N}_{2} \mathrm{O}_{4}: \mathrm{C} 70.22, \mathrm{H} 7.37$, N $6.82 \%$. Found: C 70.26, H 7.44, N $6.79 \%$. FT-IR $\left(\mathrm{KBr}, \mathrm{cm}^{-1}\right): 1628(\mathrm{C}=\mathrm{N}) .{ }^{1} \mathrm{H}-\mathrm{NMR}$ (DMSO- $d^{6}$, $\delta(\mathrm{ppm})): 1.29(\mathrm{~s}, 3 \mathrm{H}), 2.26(\mathrm{q}, 1 \mathrm{H}), 3.34(\mathrm{~s}, 2 \mathrm{H}), 3.89(\mathrm{~s}, 3 \mathrm{H}), 4.29(\mathrm{t}, 2 \mathrm{H}), 6.99(\mathrm{~d}, 1 \mathrm{H}), 7.10(\mathrm{t}, 1 \mathrm{H})$, $7.66(\mathrm{~d}, 1 \mathrm{H}), 8.64(\mathrm{~s}, 1 \mathrm{H}) .{ }^{13} \mathrm{C}-\mathrm{NMR}\left(\mathrm{DMSO}-d^{6}, \delta(\mathrm{ppm})\right): 25.86,31.10,37.08,55.88,67.23,69.69$, 76.79, 77.04, 77.29, 114.13, 118.94, 124.11, 130.32, 147.87, 152.87, 157.08.

Results and discussion. Synthesis and characterization. Herein, we explored the possibility of the preparation of two new 15- and 16-membered Schiff base macrocycles via the non-template method. This synthesis involves the reaction of dialdehydes 5,5'-dimethoxy-2,2'-(ethane-1,3-diyldioxy)dibenzaldehyde or 5,5'-dimethoxy-2,2'-(propane-1,3-diyldioxy)dibenzaldehyde with 2,2-dimethyl- 
propane-1,3-diamine in the 1:1 molar ratio in methanol in the air atmosphere at reflux. Compounds 1 and $\mathbf{2}$ are stable as solids.

In the FT-IR spectra of 1 and 2, the appearance of a strong intensity band at $1632 \mathrm{~cm}^{-1}$ and $1628 \mathrm{~cm}^{-1}$ attributed to the $v(\mathrm{C}=\mathrm{N})$ stretching vibration, provides a strong evidence for the successful preparation of $\mathbf{1}$ and $\mathbf{2}[11,12]$.

The ${ }^{1} \mathrm{H}$ and ${ }^{13} \mathrm{C}$ NMR spectra of $\mathbf{1}$ and $\mathbf{2}$ were recorded using $\mathrm{CDCl}_{3}$ as the solvent. In the downfield region of each spectrum, one singlet peak appearing at $8.74 \mathrm{ppm}$ in $\mathbf{1}$ and $8.64 \mathrm{ppm}$ in $\mathbf{2}$ is attributed to the $-\mathrm{HC}=\mathrm{N}-$ proton. The peaks are seen about $6.9-7.7 \mathrm{ppm}$, which corresponds to the protons of aromatic rings. The aliphatic protons of methyl and methoxy groups appear at about $3.88 \mathrm{ppm}$ and $1.26 \mathrm{ppm}$, respectively, as singlet signals. The $\mathrm{CH}_{2}$ groups in $\mathbf{1}$ appear as two singlet signals at $3.35 \mathrm{ppm}$ and $4.47 \mathrm{ppm}$, while the $\mathrm{CH}_{2}$ groups in 2 appear as one singlet signal at $3.34 \mathrm{ppm}$, one triplet signal at $4.29 \mathrm{ppm}$, and one quintet signal at $2.26 \mathrm{ppm}$.

In the ${ }^{13} \mathrm{C}$-NMR spectra of $\mathbf{1}$ and $\mathbf{2}$, the peaks at $55 \mathrm{ppm}$ are assigned to methyl carbon atoms. The peaks at $159.36 \mathrm{ppm}(\mathbf{1})$ and $157.08 \mathrm{ppm}(\mathbf{2})$ are due to the azomethine carbon atoms. Peaks appearing between 114-152 ppm are assigned to aromatic carbon atoms and the peaks appears between 25-77 ppm are assigned to aliphatic carbon atoms.

Molecular geometry of $\mathbf{1}$ and 2. The molecular structures of titled compounds $\mathbf{1}$ and $\mathbf{2}$ with the atom numbering scheme are shown in Figs. 1 and 2, respectively. The molecules of both compounds are not planar. The bond lengths and angles of $\mathbf{1}$ and $\mathbf{2}$ are very close to the corresponding ones in the Cambridge structural database [11]. The N11-C10 (1.264(5)), N15-C16 (1.262(5)), N2-C1 $(1.258(3))$, and $\mathrm{N} 1-\mathrm{C} 19(1.255(3))$ bond distances in $\mathbf{1}$ and $\mathbf{2}$ are consistent with the distances of the $\mathrm{C}=\mathrm{N}$ double bonds, while the $\mathrm{N} 11-\mathrm{C} 12$ (1.462(5)), $\mathrm{N} 15-\mathrm{C} 14$ (1.453(5)), N2-C22 (1.450(3)), and $\mathrm{N} 1-\mathrm{C} 20(1.454(3))$ bond distances in $\mathbf{1}$ and $\mathbf{2}$ are consistent with the distances of the $\mathrm{C}-\mathrm{N}$ single bonds. The $\mathrm{C} 12-\mathrm{N} 11-\mathrm{C} 10 \quad(117.34(10)), \quad \mathrm{C} 16-\mathrm{N} 15-\mathrm{C} 14 \quad(117.55(9)), \quad \mathrm{C} 19-\mathrm{N} 1-\mathrm{C} 20$ $(119.83(19))$, and $\mathrm{C} 1-\mathrm{N} 2-\mathrm{C} 22(119.1(2))$ bond angles are consistent with the $s p^{2}$ hybrid character of $\mathrm{N} 11, \mathrm{~N} 15, \mathrm{~N} 1$, and $\mathrm{N} 2$ atoms. The distances between the atoms $\mathrm{N} 15 \cdots \mathrm{N} 11, \mathrm{O} 1 \cdots \mathrm{O} 19, \mathrm{~N} 1 \cdots \mathrm{N} 2$, and $\mathrm{O} 3 \cdots \mathrm{O} 2$ are $3.788 \AA, 2.743 \AA, 3.788 \AA$, and $3.865 \AA$ in $\mathbf{1}$ and $\mathbf{2}$, respectively. The $\mathrm{O} \cdots \mathrm{O}$ distance is shorter in 1 than the similar distance in $\mathbf{2}$, while the $\mathrm{N} \cdots \mathrm{N}$ distances is equal in both compounds. In both compounds $\mathbf{1}$ and $\mathbf{2}$, there are four distances between $\mathrm{N}$ and $\mathrm{O}$ atoms: $\mathrm{O} 1 \cdots \mathrm{N} 15=4.709 \AA$, $\mathrm{O} 1 \cdots \mathrm{N} 11=3.923 \AA, \mathrm{O} 19 \cdots \mathrm{N} 11=4.655 \AA$, and $\mathrm{O} 19 \cdots \mathrm{N} 15=3.935 \AA$ for 1 and $\mathrm{O} 3 \cdots \mathrm{N} 2=5.501 \AA$, $\mathrm{O} 3 \cdots \mathrm{N} 1=4.136 \AA, \mathrm{O} 2 \cdots \mathrm{N} 1=5.709 \AA$, and $\mathrm{O} 2 \cdots \mathrm{N} 2=4.102 \AA$.

In $\mathbf{1}$, there are two intermolecular hydrogen bonds of the $\mathrm{C}-\mathrm{H} \cdots \mathrm{O}$ type, while in $\mathbf{2}$, the potential non-classical C $-\mathrm{H} . . . \mathrm{O}$ hydrogen bonds (Tables 1 ) have rather sharp angles between 116 and $130^{\circ}$, as

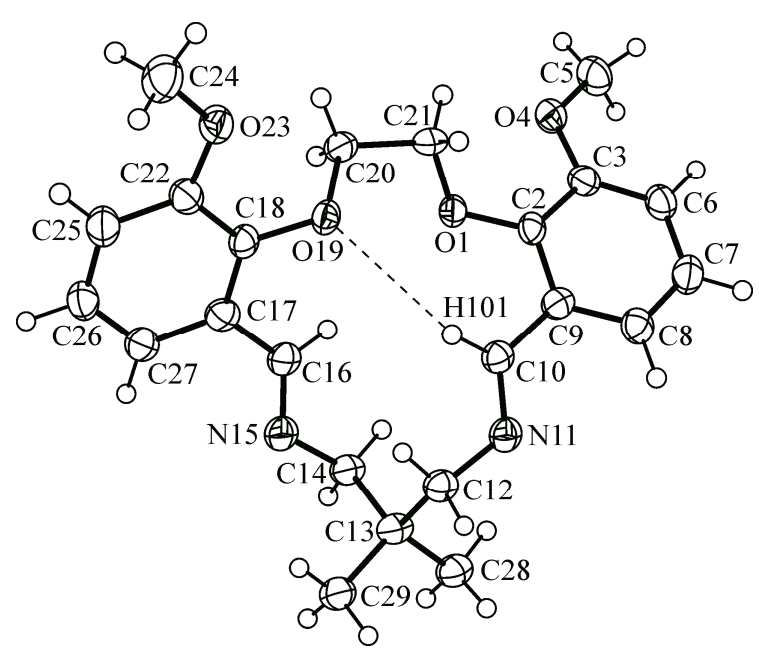

Fig. 1. Molecular structure of compound 1. Thermal ellipsoids have been drawn at the $50 \%$ probability level

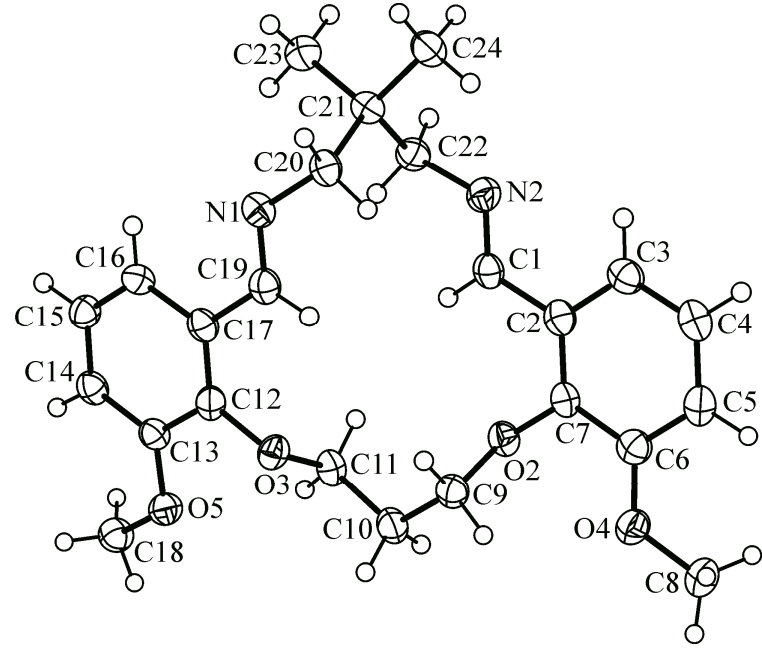

Fig. 2. Molecular structure of compound 2. Thermal ellipsoids have been drawn at the $50 \%$ probability level 
$\mathrm{T} \mathrm{a} \mathrm{b} 1$ e 1 compared with 1 where the angles are

Hydrogen bonds parameters $(\AA$, deg.) for $\mathbf{1}$ and $\mathbf{2}$

\begin{tabular}{l|c|c|c|c}
\hline \multicolumn{1}{c|}{$D-\mathrm{H} \cdots A$} & $D-\mathrm{H}$ & $\mathrm{H} \cdots A$ & $D \cdots A$ & $D-\mathrm{H}^{\cdots} A$ \\
\hline $\mathrm{C} 24-\mathrm{H} 243 \cdots \mathrm{O} 4^{\mathrm{i}}$ & 0.960 & 2.567 & $3.489(5)$ & 161.1 \\
$\mathrm{C} 5-\mathrm{H} 2 \mathrm{c} 5 \cdots \mathrm{O} 23^{\mathrm{ii}}$ & 0.960 & 2.577 & $3.525(5)$ & 169.8 \\
$\mathrm{C} 8-\mathrm{H} 8 \mathrm{~b} \cdots \mathrm{O} 5^{\mathrm{i}}$ & $0.961(2)$ & $2.5299(16)$ & $3.237(3)$ & $130.46(15)$ \\
$\mathrm{C} 5-\mathrm{H} 9 \mathrm{~b} \cdots \mathrm{O} 4$ & $0.969(2)$ & $2.4677(17)$ & $3.024(3)$ & $116.30(14)$ \\
$\mathrm{C} 11-\mathrm{H} 11 \mathrm{~b} \cdots \mathrm{O} 5$ & $0.971(2)$ & $2.4197(17)$ & $2.997(3)$ & $117.71(15)$
\end{tabular}

Symmetry codes for 1 : ${ }^{\mathrm{i}} x-1 / 2,-y+3 / 2, z-1 / 2 ;{ }^{\text {ii }} x,-y+1, z+1 / 2$. Symmetry code for 2 : ${ }^{\mathrm{i}}-x,-y+1,-z+1$. between 161 and $170^{\circ}$. However, the H...A distance is also shorter so we may consider these bonds. Unlike 1, the molecules are only connected to dimers through bifurcated hydrogen bonds.

Crystallographic data (excluding structure factors) for the structures reported in this paper have been deposited with the Cambridge Crystallographic Center, CCDC Nos. 1050169

(1) and 1050170 (2). Copies of the data can be obtained free of charge on application to the Director, CCDC, 12 Union Road, Cambridge CB2 1EZ, UK, fax: +44 1223336 033, e-mail: deposit@ccdc.cam.ac.uk or http:www.ccdc.cam.ac.uk.

We acknowledge the Golestan University (GU) for partial support of this work. Structure analysis was supported by the project No.15-12653S of the Czech Science Foundation.

\section{REFERENCES}

1. Ilhan S., Temel H., Kilic A., Tas E. // Trans. Met. Chem. - 2007. - 32. - P. 1012 - 1017.

2. Khandar A.A., Hosseini-Yazdi S.A., Khatamian M., Zarei S.A. // Polyhedron. - 2010. - 29. - P. 995 - 1000.

3. Salavati-Niasari M., Amiri A. // Transition Met. Chem. - 2006. - 31. - P. 157 - 162.

4. Al-Radadi N.S., Al-Ashgar S.M., Mostafa M.M. // J. Inclusion Phenom. Macrocyclic Chem. - 2011. - 69. - P. $157-165$.

5. Yilmaz I., Ilhan S., Temel H., Kilic A. // J. Inclusion Phenom. Macrocyclic Chem. - 2009. - 63. - P. 163 169.

6. Keypour H., Shayesteh M., Sharifi-Rad A., Salehzadeh S., Khavasi H., Valencia L. // Organomet. Chem. - 2008. - 693. - P. 3179 - 3187.

7. Khandar A.A., Hosseini-Yazdi S.A., Zarei S.A. // Inorg. Chim. Acta. - 2005. - 358. - P. 3211 - 3217.

8. Ilhan S., Temel H. // Indian J. Chem. - 2008. - 47A. - P. 378 - 382.

9. Ilhan S., Temel H. // Transition Met. Chem. - 2007. - 32. - P. $1039-1046$.

10. Khanmohammadi H., Keypour H., Fard M.S., Abnosi M.H. // J. Inclusion Phenom. Macrocyclic Chem. - 2009. - 63. - P. 97 - 108.

11. Reyes-Marquez V., Sanchez M., Hopfl H., Lara K.O. // J. Inclusion Phenom. Macrocyclic Chem. - 2009. - 65. - P. $305-315$.

12. Singh M.S., Verma R.K., Singh S., Gupta A. // Indian J. Chem. - 2012. - 51B. - P. 866 - 870.

13. Borisova N.E., Reshetova M.D., Ustynyuk Y.A. // Chem. Rev. - 2007. - 107. - P. 46 - 79.

14. Srimurugan S., Suresh P., Pati H.N. // J. Inclusion Phenom. Macrocyclic Chem. - 2007. - 59. - P. 383 388.

15. Zhen M., Shi-Xiong L. // Chinese J. Struct. Chem. - 2003. - 22. - P. 553 - 557.

16. Correa W.H., Scott J.L. // Molecules. - 2004. - 9. - P. 513 - 519.

17. Lee C.-H., Ka J.-W., Won D.-H. // Tetrahedron Lett. - 1999. - 40. - P. $6799-6802$.

18. Won D.-H., Lee C.-H. // Tetrahedron Lett. - 2001. - 42. - P. $1969-1972$.

19. Abbas A.A. // Tetrahedron Lett. - 2004. - 60. - P. $1541-1548$.

20. Lee C.-H., Oh K.-T. // Tetrahedron Lett. - 1999. - 40. - P. 1921 - 1924.

21. Houjou H., Nagawa Y., Hiratani K. // Tetrahedron Lett. - 2001. - 42. - P. 38761 - 3863.

22. Fan Z., Diao C.-H., Guo M.-J., Yu M., Chen X. // Acta Crystallogr. - 2005. - E61 - P. o4004/o4005.

23. Ali Q., Shah M.R., Ng S.W. // Acta Crystallogr. - 2010. - E66. - P. o1620.

24. Sheldrick M. // Acta Crystallogr. - 2008. - A64. - P. 112.

25. Petricek V., Dusek M., Palatinus L. // Z. Kristallogr. - 2014. - 229. - P. 345.

26. Farrugia L.J. // J. Appl. Crystallogr. - 1997. - 30. - P. 656. 